\title{
Mindfulness-Based Cognitive Therapy for Late- Life Depression: a Randomised Controlled Trial
}

\author{
VWY Shih, WC Chan, OK Tai, HL Wong, CPW Cheng, CSM Wong
}

\begin{abstract}
Background: Rumination and overgeneral autobiographical memory are dysfunctional cognitions commonly found in older adults with depression. The theoretical underpinnings of mindfulnessbased cognitive therapy (MBCT) address the ruminative tendencies and the non-specific retrieval of autobiographical memories. This study aims to examine the efficacy and cognitive mechanisms of MBCT in older adults with active depressive symptoms.

Methods: 57 older adults (mean age, 70 years) with normal cognition and mild to moderate depressive symptoms were randomly allocated to either the MBCT group or the active control group for 8 weeks. The MBCT group consisted of eight 2-hour weekly sessions and a 7-hour full-day retreat, with different themes for each class, guided mindfulness exercises, feedback and discussion, homework review, and psychoeducation. The active control group comprised a 1-hour physical exercise and a standardised health education of the specific theme with group discussion (eg fall prevention, chronic pain). Participants were assessed before and after the 8-week intervention for four outcome measures: the Hamilton Depression Rating Scale (HAMD), the Ruminative Response Scale (RRS), the Autobiographical Memory Test (AMT), and the Mindful Attention Awareness Scale (MAAS).

Results: There was a significant reduction in severity of depressive symptoms (HAMD score) in both the MBCT group $\left(\mathrm{F}(1,27)=35.9, \mathrm{p}<0.001, \eta^{2}=0.57\right)$ and the active control group $(\mathrm{F}(1,28)=9.29$, $\left.\mathrm{p}<0.01, \eta^{2}=0.24\right)$, but only the MBCT group showed substantial improvements in autobiographical memory specificity (AMT score), rumination (RRS score), and mindfulness (MAAS score).

Conclusion: Although both MBCT and active control programme decrease the severity of depressive symptoms in older adults, only MBCT improves AMS, rumination, and mindfulness. Our findings provide empirical support for the theoretical underpinnings of MBCT. Older adults with more severe depression and more severe dysfunctional cognition may benefit more from the specific therapeutic effects of MBCT.
\end{abstract}

Key words: Aged; Depression; Memory, episodic; Mindfulness; Rumination, cognitive

Vivian WY Shih, Department of Psychiatry, LKS Faculty of Medicine, The University of Hong Kong

Wai-Chi Chan, Department of Psychiatry, LKS Faculty of Medicine, The University of Hong Kong

On-Ki Tai, Department of Psychiatry, LKS Faculty of Medicine, The University of Hong Kong

Hau-Lam Wong, Department of Psychiatry, LKS Faculty of Medicine, The University of Hong Kong

Calvin PW Cheng, Department of Psychiatry, LKS Faculty of Medicine, The University of Hong Kong

Corine SM Wong, Department of Psychiatry, LKS Faculty of Medicine, The University of Hong Kong

Address for correspondence: Wai-Chi Chan, Department of Psychiatry, 2/F New Clinical Building, Queen Mary Hospital, Pokfulam, Hong Kong.

Email:waicchan@hku.hk

Submitted: 17 August 2020; Accepted: 17 December 2020

\section{Introduction}

Depression is a common mental disorder in older adults and accounts for a large burden on public healthcare. ${ }^{1}$ Pharmacological interventions are effective in alleviating depressive symptoms, ${ }^{2}$ but they do not address the underlying dysfunctional cognitive processes associated with depression.

Rumination is a dysfunctional cognition commonly found in people with depression. ${ }^{3,4}$ It is characterised by a propensity to focus attention on oneself, one's mood and unresolved problems. Instead of seeking constructive solutions, ruminators often over-analyse the possible meanings, implications, causes, and consequences in an abstract and evaluative manner. ${ }^{5}$ Ruminative responses to distress are predictive of the onset, recurrence, duration, and severity of a depressive episode. ${ }^{5,6}$ Older adults with ruminative tendencies are likely to experience a more frequent, severe, and prolonged depressive episode, which makes them more susceptible to medical and cognitive problems. ${ }^{7}$ Ruminative tendency in older adults plays a role in increasing vulnerability to further depressive episodes because of executive deterioration that impair inhibitory ability and attentional control to disseminate and regulate ruminative thoughts. ${ }^{4}$

Overgeneral autobiographical memory is another dysfunctional cognition closely related to the severity and 
duration of a depressive episode.$^{89}$ It is characterised by reduced autobiographical memory specificity (AMS) and a higher propensity to recall an overgeneral event or a generic summary of repeated events. It is hypothesised that autobiographical memories are stored in the self-memory system, within which memory representations are arranged from general to specific levels in a hierarchical structure. ${ }^{10}$ Overgeneral memories are a result of the early termination in the generative retrieval search, truncating at a level at which only the semantic meanings of the search cue or categoric information about the event are accessible. Reduced AMS is associated with impaired problem solving and attainment of future goals, ${ }^{11}$ both of which inevitably reinforce negative emotions. Reduced AMS can be particularly prominent in late adulthood because of the natural decline in executive control, ${ }^{12,13}$ increased difficulty in disseminating ruminative tendencies in the retrieval search, and changes in information processing styles and emotional strategies. ${ }^{14,15}$

Mindfulness-based cognitive therapy (MBCT) mitigates the effects of rumination and overgeneral autobiographical memory by fostering cognitive flexibility and more adaptive coping strategies to regulate emotions. Mindfulness is a psychological process of purposefully paying attention to present moment experiences in a non-judgemental manner. It is originated from Buddhist philosophy and connotes an open, accepting, and curious orientation to internal and external experiences at present without further evaluating their causes, consequences, implications, desirability, or correctness. MBCT combines mindfulness practices and cognitive-behavioural elements to enhance participants' understanding of the interconnections among thoughts, emotions, bodily sensations, and behaviours. Individuals are trained to increase their level of mindfulness by attending to thoughts, mood, or bodily sensations when they are experienced instead of automatically avoiding or acting on them with habitual practices that may be maladaptive.

MBCT addresses the underlying mechanisms of dysfunctional cognitions found in individuals with depression. Mindfulness enhances an individual's cognitive flexibility through conscious and continuous awareness of present-moment experiences (eg breathing). ${ }^{16}$ In addition, attentional switching skills and inhibitory skills are trained when arising thoughts, feelings, and sensations are redirected from further elaborative processing to another attentional focus. As rumination is characterised by difficulty in switching attention away from negative thoughts, ${ }^{17}$ better attentional switching ability allows rumination to be interrupted during practices of mindfulness, in which incoming thoughts that rise to the stream of consciousness are detected and redirected back to the present moment. Enhanced cognitive flexibility may benefit the retrieval of more specific autobiographical memories among older adults who experience greater difficulty in switching, updating, and holding information in their working memory as a result of age-related cognitive decline. ${ }^{18,19}$ Practising mindfulness also improves one's ability to self-regulate emotional states via a meta-cognitive process of observing one's mental processes from a decentred perspective.

MBCT was originally designed as a relapse prevention programme for recurrent depressive disorder, ${ }^{20}$ with promising effects on reducing the risk of relapse $\mathrm{e}^{21,22}$ and on increasing individuals' capacity for mindfulness. ${ }^{23,24}$ MBCT was then extended to alleviate symptoms of depression in currently depressed individuals on the basis that the underlying vulnerabilities for relapse and maintenance of active depressive symptoms are activated by the same mechanism (ie, depressive rumination). MBCT has demonstrated satisfactory treatment effects on reducing active depressive symptoms in younger adults. ${ }^{25,26}$ However, studies of the efficacy of MBCT, particularly its immediacy effects, on older populations are limited, ${ }^{27-29}$ presumably owing to differences in sample size and baseline depression levels from a mixture of sampling populations that ranged from those in remission to those currently depressed to those non-depressed with chronic back pain. Given that rumination and reduced AMS are potentially more prominent in depressed older adults, we aimed to examine the efficacy and cognitive mechanisms of MBCT in older adults with active depressive symptoms.

\section{Methods}

This single-blind randomised controlled study was approved by the Institutional Review Board of the University of Hong Kong/ Hospital Authority Hong Kong West Cluster (reference: UW 17-488). It adopted a $2 \times 2$ repeatedmeasures design with two intervention groups (MBCT and active control) and two time-point assessments (before and after the 8-week intervention). Scores on each assessment were analysed as four separate dependent variables.

The sample size was calculated using $\mathrm{G}^{*}$ Power 3.1 based on a study that examined the effectiveness of mindfulness-based stress reduction on community-dwelling older adults with depressive symptoms ${ }^{30}$ Assuming a twotailed alpha of 5\%, a power of $80 \%$, and an attrition rate of $20 \%, 54$ participants (27 in each group) were required to detect a change in treatment score of 2.56 on the Geriatric Depression Scale.

Of 87 individuals aged $\geq 60$ years recruited from online mailing lists and elderly community centres through flyers promotions, 57 were included who had mild to moderate depressive symptoms (score of 8 to 18 on Hamilton Depression Rating Scale [HAMD]) and normal cognitive functioning (score of $\geq 22$ on Montreal Cognitive Assessment $[\mathrm{MoCA}])$. Only those with mild to moderate depressive symptoms were included, because the severity of depression affects the efficacy of psychotherapy and because monotherapies may not be effective for those with a score of $>20$ on the HAMD ${ }^{31}$ Those with other psychiatric/ medical diagnoses such as major neurocognitive disorder, active psychotic disorder, bipolar affective disorder, and 
life-threatening medical comorbidities were excluded, as were those who practised meditation or mindfulness regularly.

Each participant received a detailed explanation of the study design and scheduled dates for interventions and procedures before giving written informed consent. Participants were assigned to the MBCT group $(n=28)$ or the active control group $(n=29)$ using a random permuted block design with a block size of 8 .

The MBCT programme adhered closely to the previously reported MBCT protocol. ${ }^{20}$ It consisted of eight 2-hour weekly sessions and a 7-hour full-day retreat, with different themes for each class, guided mindfulness exercises, feedback and discussion, homework review, and psychoeducation. The programme was delivered in Cantonese and led by a MBCT teacher who received formal training organised by the Oxford Mindfulness Centre and the Hong Kong Centre for Mindfulness.

The active control group received equivalent exposure time on specific health-related themes (eg fall prevention, chronic pain) for each class to account for the non-specific therapeutic effects in the MBCT group such as social support, interactions with the facilitator, and an expectation of positive outcomes. Each session comprised a 1-hour physical exercise guided by a physical trainer and a standardised health education of the specific theme with group discussion. Participants were given diagrammed step-by-step exercises handouts and encouraged to practise the exercises at home.

Participants were assessed before and after the 8-week intervention by the primary investigator and two trained research team members who were blinded to the group assignment. Sociodemographic and clinical data including age, sex, education, occupation, diagnosed mental illness (if any), chronic illness (if any), and prior experience in meditation were collected at baseline. Outcome measures included the HAMD, the Ruminative Response Scale (RRS), the Autobiographical Memory Test (AMT), the

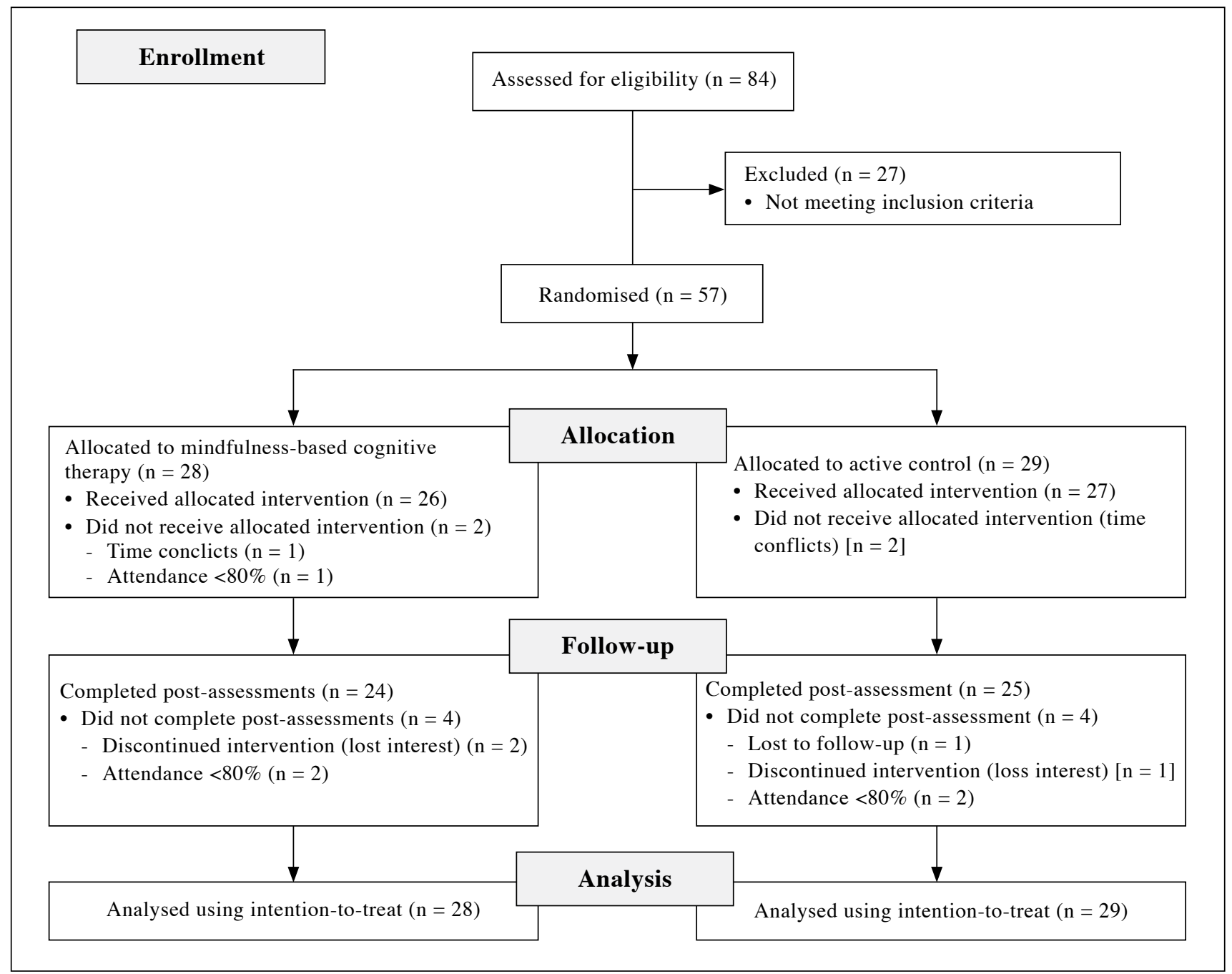

Figure. Flowchart of recruitment of participants 
Mindful Attention Awareness Scale (MAAS), and the MoCA.

The HAMD is a 17 -item semi-structured questionnaire to assess the severity of symptoms of depression, including depressed mood, feelings of guilt, suicidal ideation, insomnia, agitation, retardation, anxiety, somatic symptoms, weight loss, and genital symptoms. ${ }^{32}$ Higher scores indicate greater severity. The Chinese version of the HAMD has good internal reliability (Cronbach's $\alpha=0.71$ ). ${ }^{33}$

The RRS is a 22-item self-reported questionnaire to assess ruminative coping styles to depressed mood. ${ }^{6}$ It contains components concerning 'brooding', 'reflective' and 'symptom-focused' ruminative patterns. Responses are rated on a 4-point Likert scale, with higher scores indicating greater levels of rumination. The Chinese version of the RRS has good internal reliability for brooding $(\alpha=0.77)$ and reflective $(\alpha=0.71)$ components. ${ }^{34}$

The AMT is used to quantify the specificity of autobiographical memory. ${ }^{35}$ It contains five positively valenced cue words (eg, happy, comfortable) and five negatively valenced cue words (eg, hopeless, worried). For each cue word, participants were asked to generate a specific memory of a personal event that happened within the course of 1 day. Participants were given two practice words before the actual test to familiarise with the procedures and task requirements. The generated memories were recorded and coded according to the scoring criteria (Table 1). Higher scores indicate a more specific memory base. An equivalent list of 10 cue words was compiled to make two matched sets (A and B) for assessment before and after intervention to minimise practice effects.

The MAAS is a self-reported questionnaire to assess trait mindfulness. ${ }^{36}$ It contains 15 items rated on a 6-point Likert scale. Lower scores indicate higher levels of trait mindfulness. The Chinese version of the MAAS has good internal reliability $(\alpha=0.85){ }^{37}$

The MoCA is a screening tool for cognitive impairment. It comprises seven domains: visuospatial and executive functioning, naming, attention, language, abstract reasoning, delayed recall, and orientation. The total score is 30; higher scores indicate better cognitive ability. The Hong Kong version of MoCA has good internal reliability $(\alpha=$ $0.72) .{ }^{38}$

Baseline outcome measures between the MBCT group and the active control group were compared using the independent $t$-test, Mann-Whitney $U$ test, or Chi-squared test. To determine the effects of MBCT relative to active control programme, mixed-factorial ANOVA was used to examine the group $\times$ time interaction for the four outcome measures. Intention-to-treat analysis was used; multiple imputation was used for missing data. ${ }^{39}$ To investigate the differences in the AMT responses between groups at each time point, the relative proportion of the various AMT responses were computed. Bonferroni-adjusted simple effect analyses were conducted to examine the effects of time for both groups and to compare the difference between groups after intervention.

\section{Results}

Shapiro-Wilk analysis indicated a nonparametric nature for age and scores of the HAMD, AMT, RRS, and MoCA. The MBCT and active control groups were comparable in terms of baseline characteristics (Table 2). Of 28 participants in the MBCT group and 29 participants in the active control group, four in each group did not complete post-assessment owing to attendance $<80 \%$, loss of interest, or lost to follow-up. Thus, 24 and 25 participants in the respective groups were compared. Completers and non-completers were comparable in terms of baseline characteristics.

There was a significant group $\times$ time interaction for the HAMD score $\left(F(1,55)=8.28, p<0.01, \eta^{2}=0.13\right.$, Table 3). In the Bonferroni-adjusted simple effect analysis, the HAMD score significantly reduced after intervention in both the MBCT group $\left(\mathrm{F}(1,27)=39.6, \mathrm{p}<0.001, \eta^{2}=\right.$ $0.59)$ and the active control group $(\mathrm{F}(1,28)=13.0, \mathrm{p}<0.01$,

Table 1. Scoring criteria of the Autobiographical Memory Test

\begin{tabular}{|lcl|}
\hline $\begin{array}{l}\text { Specificity of } \\
\text { memories }\end{array}$ & Score & Criteria \\
\hline $\begin{array}{l}\text { Specific memories } \\
\text { Extended memories }\end{array}$ & 4 & $\begin{array}{l}\text { Memory of one single personal event that occurred at a particular place and time } \\
\text { within the course of one day (eg, the day I got married). }\end{array}$ \\
\hline Categoric memories & 2 & $\begin{array}{l}\text { Memory of one single personal event that lasted for }>1 \text { day (eg, my weekend in } \\
\text { London). }\end{array}$ \\
\hline Semantic associates & 1 & $\begin{array}{l}\text { Thematic summaries of events that happened multiple times (eg, whenever I } \\
\text { played games with my brother). }\end{array}$ \\
\hline Omissions & 0 & $\begin{array}{l}\text { Inability to generate a response within 1 minute, irrelevant information or } \\
\text { memories and duplicated event. }\end{array}$ \\
\hline
\end{tabular}


Table 2. Baseline characteristics of participants

\begin{tabular}{|lccc|}
\hline Variable & $\begin{array}{c}\text { Mindfulness-based cognitive } \\
\text { therapy }(\mathbf{n = 2 8})^{*}\end{array}$ & Active control $(\mathbf{n}=\mathbf{2 9})^{*}$ & p Value \\
Age, $\mathrm{y}$ & $69.69 \pm 7.48)$ & $70.86 \pm 5.80$ & 0.37 \\
\hline No. $(\%)$ of women & $25(89)$ & $25(86)$ & 0.72 \\
\hline Education, $\mathrm{y}$ & $9.21 \pm 4.59$ & $8.21 \pm 4.79$ & 0.42 \\
\hline Hamilton Depression Rating Scale & $13.36 \pm 3.41$ & $12.17 \pm 3.45$ & 0.20 \\
\hline Ruminative Response Scale & $49.79 \pm 11.29$ & $48.31 \pm 11.51$ & 0.58 \\
\hline Autobiographical Memory Test & $18.89 \pm 5.38$ & $17.96 \pm 5.23$ & 0.51 \\
\hline Mindful Attention Awareness Scale & $54.39 \pm 9.71$ & $54.10 \pm 9.47$ & 0.91 \\
\hline Montreal Cognitive Assessment & $26.32 \pm 2.41$ & $25.41 \pm 2.48$ & 0.15 \\
\hline
\end{tabular}

Data are presented as mean \pm standard deviation unless otherwise stated

Table 3. Group $x$ time interaction of five outcomes using intention-to-treat analysis

\begin{tabular}{|c|c|c|c|c|c|c|c|c|}
\hline \multirow[t]{2}{*}{ Outcome } & \multicolumn{3}{|c|}{$\begin{array}{c}\text { Mindfulness-based cognitive } \\
\text { therapy }(n=28)\end{array}$} & \multicolumn{3}{|c|}{ Active control $(n=29)$} & \multirow{2}{*}{$\begin{array}{c}\text { Group } \\
\text { x time } \\
\text { interaction, } \\
\text { p value }\end{array}$} & \multirow{2}{*}{$\begin{array}{c}\text { Effect } \\
\text { size, } \\
\text { partial } \eta^{2}\end{array}$} \\
\hline & Baseline* & $\begin{array}{c}\text { Post- } \\
\text { intervention* }\end{array}$ & $\begin{array}{l}\text { Mean } \\
\text { change }\end{array}$ & Baseline* & $\begin{array}{c}\text { Post- } \\
\text { intervention* }\end{array}$ & $\begin{array}{l}\text { Mean } \\
\text { change }\end{array}$ & & \\
\hline $\begin{array}{l}\text { Hamilton } \\
\text { Depression Rating } \\
\text { Scale }\end{array}$ & $13.36 \pm 3.41$ & $7.02 \pm 4.54$ & -6.34 & $12.17 \pm 3.45$ & $9.44 \pm 4.77$ & -2.74 & 0.006 & 0.131 \\
\hline $\begin{array}{l}\text { Ruminative } \\
\text { Response Scale }\end{array}$ & $49.79 \pm 11.29$ & $42.85 \pm 9.51$ & -6.94 & $48.31 \pm 11.51$ & $48.95 \pm 9.27$ & 0.64 & 0.020 & 0.095 \\
\hline $\begin{array}{l}\text { Autobiographical } \\
\text { Memory Test }\end{array}$ & $18.89 \pm 5.38$ & $24.85 \pm 6.45$ & 5.96 & $17.96 \pm 5.12$ & $20.03 \pm 5.20$ & 2.07 & 0.013 & 0.107 \\
\hline $\begin{array}{l}\text { Mindful Attention } \\
\text { Awareness Scale }\end{array}$ & $54.39 \pm 9.71$ & $46.20 \pm 11.24$ & -8.19 & $54.10 \pm 9.47$ & $53.50 \pm 8.55$ & -0.6 & 0.020 & 0.094 \\
\hline
\end{tabular}

Data are presented as mean \pm standard deviation

$\eta^{2}=0.32$ ); the post-intervention HAMD score was lower (but not significantly) in the MBCT group than in the active control group $(\mathrm{p}=0.055)$.

There was a significant group $\times$ time interaction for the RRS score $\left(F(1,55)=5.76, p<0.05, \eta^{2}=0.095\right)$. In the Bonferroni-adjusted simple effect analysis, the RRS score significantly reduced after intervention in the MBCT group only $\left(\mathrm{F}(1,27)=7.48, \mathrm{p}<0.01, \eta^{2}=0.22\right)$; the postintervention RRS score was significantly lower in the MBCT group than in the active control group $(\mathrm{F}(1,55)=$ $\left.6.01, \mathrm{p}<0.05, \eta^{2}=0.099\right)$.

There was a significant group $\times$ time interaction for the AMT score $\left(F(1,55)=6.57, p<0.05, \eta^{2}=0.11\right)$. In the Bonferroni-adjusted simple effect analysis, the AMT score significantly increased after intervention in both the MBCT group $\left(F(1,27)=21.9, p<0.001, \eta^{2}=0.45\right)$ and the active control group $\left(\mathrm{F}(1,28)=5.97, \mathrm{p}<0.05, \eta^{2}=0.17\right)$; the post-intervention AMT score was significantly higher in the MBCT group than the active control group $(F(1,55)=9.68$, $\left.\mathrm{p}<0.01, \eta^{2}=0.15\right)$.

There was a significant group $\times$ time interaction for the MAAS score $\left(F(1,55)=5.74, p<0.05, \eta^{2}=0.09\right)$. In the Bonferroni-adjusted simple effect analysis, the MAAS score (ie, improvement in state mindfulness) significantly reduced after intervention in the MBCT group only $\left(\mathrm{F}(1,27)=8.69, \mathrm{p}<0.01, \eta^{2}=0.24\right)$; the post-intervention MAAS score was significantly lower in the MBCT group than in the active control group $(\mathrm{F}(1,55)=7.64, \mathrm{p}<0.01$, $\eta^{2}=0.12$ ).

To determine the treatment effects on different levels of memory specificity, the relative proportions of the five AMT responses were compared between groups and 
Table 4. The relative proportions of the five responses of the Autobiographical Memory Test by group and time

\begin{tabular}{|c|c|c|c|c|c|}
\hline \multirow[t]{2}{*}{ Responses } & \multicolumn{2}{|c|}{$\begin{array}{l}\text { Mindfulness-based cognitive } \\
\text { therapy }(n=28)\end{array}$} & \multicolumn{2}{|c|}{ Active control $(n=29)$} & \multirow{2}{*}{$\begin{array}{l}\text { Group } x \text { time } \\
\text { interaction } \\
\text { effects, } p \text { value }\end{array}$} \\
\hline & Baseline $^{*}$ & $\begin{array}{c}\text { Post- } \\
\text { intervention }\end{array}$ & Baseline $^{*}$ & $\begin{array}{c}\text { Post- } \\
\text { intervention* }\end{array}$ & \\
\hline Omissions & $0.19 \pm 0.16$ & $0.09 \pm 0.11$ & $0.27 \pm 0.15$ & $0.16 \pm 0.15$ & 0.681 \\
\hline Semantic associates & $0.25 \pm 0.15$ & $0.15 \pm 0.15$ & $0.19 \pm 0.16$ & $0.22 \pm 0.15$ & 0.022 \\
\hline Categoric memories & $0.28 \pm 0.17$ & $0.31 \pm 0.15$ & $0.24 \pm 0.14$ & $0.30 \pm 0.15$ & 0.485 \\
\hline Extended memories & $0.04 \pm 0.07$ & $0.08 \pm 0.11$ & $0.05 \pm 0.09$ & $0.07 \pm 0.12$ & 0.697 \\
\hline Specific memories & $0.24 \pm 0.14$ & $0.37 \pm 0.26$ & $0.25 \pm 0.18$ & $0.24 \pm 0.15$ & 0.024 \\
\hline
\end{tabular}

Data are presented as mean \pm standard deviation

between times (Table 4). For the response of omissions, the interaction effect was not significant $(\mathrm{p}=0.681)$, but the main effect of time was significant $(\mathrm{F}(1,55)=25.0$, $\mathrm{p}<0.001, \eta^{2}=0.31$ ). Both groups tended to generate fewer response of omissions. In the Bonferroni-adjusted simple effect analysis, the proportion of response of omissions significantly reduced after intervention in both the MBCT group $\left(F(1,27)=8.90, p<0.001, \eta^{2}=0.25\right)$ and the active control group $\left(F(1,28)=17.69, p<0.001, \eta^{2}=0.39\right)$. The proportion of responses of omissions was higher (but not significantly) in the MBCT group than in the active control group at baseline $\left(F(1,55)=3.94, p=0.052, \eta^{2}=0.067\right)$ and after intervention $(p=0.056)$. There was a significant group $\times$ time interaction for the response of semantic associates $\left(F(1,55)=5.51, \mathrm{p}<0.05, \eta^{2}=0.091\right)$. In the Bonferroni-adjusted simple effect analysis, the proportion of the response of semantic associates significantly reduced after intervention in the MBCT group only $(\mathrm{F}(1,27)=4.85$, $\left.\mathrm{p}<0.05, \eta^{2}=0.15\right)$; there was no significant difference between groups after intervention $(p=0.072)$. There was no significant main effect of time $(p=0.154)$ or group $x$ time interaction $(p=0.485)$ for the response of categoric memories. Similarly, there was no significant main effect of time $(\mathrm{p}=0.147)$ or group $\times$ time interaction $(\mathrm{p}=0.697)$ for the response of extended memories. There was a significant group $\times$ time interaction for the response of specific memories $\left(F(1,55)=5.35, \mathrm{p}<0.05, \eta^{2}=0.089\right)$. In the Bonferroni-adjusted simple effect analysis, the proportion of the response of specific memories significantly increased after intervention in the MBCT group only $(\mathrm{F}(1,27)=6.95$, $\left.\mathrm{p}<0.05, \eta^{2}=0.21\right)$. After intervention, the proportion of the response of specific memories was significantly greater in the MBCT group than in the active control group $(\mathrm{F}(1,55)$ $=5.29, \mathrm{p}<0.05, \eta^{2}=0.09$ ).

\section{Discussion}

In the present study, depressive symptoms significantly reduced after intervention in both the MBCT and the active control groups. The post-intervention HAMD score was lower (but not significantly) in the MBCT group than in the active control group. The effect size of the active control group was smaller than that of the MBCT group. Improvements in dysfunctional cognition and trait mindfulness were significant only in the MBCT group. MBCT alleviated depressive symptoms in older adults, with efficacy comparable to that reported in younger samples. ${ }^{25,26}$

The post-intervention level of rumination was significantly lower in the MBCT group than in the active control group. In a systematic review and meta-analysis of 11 randomised controlled studies, MBCT resulted in a moderate reduction in rumination, after adjusting for the treatment phase and the number of previous depressive episodes. ${ }^{40}$ In the present study, MBCT had a comparable effect size with active control programme. This indicates that a reduction in the rumination level was a specific therapeutic component of MBCT, which can benefit older adults despite their vulnerability and difficulty in regulating ruminative behaviours. ${ }^{4,41}$ The active control group had no significant improvement in rumination after intervention, despite having a reduction in depressive symptoms. This indicates that rumination is not merely a consequence of depression; rather it is a trait-like tendency that remains elevated when depressive symptoms improved. ${ }^{6}$

The reduction in rumination levels in the MBCT group can be due to the theoretical underpinnings of MBCT. ${ }^{42}$ Mindfulness training enables older adults to focus their attention on present-moment experiences while inhibiting elaborative processing that is often associated with pastoriented and non-directed ruminations. Mindfulness training and cognitive-behavioural education cultivate an individual's awareness over internal experiences such as ongoing thoughts and changing emotional states and physiological reactions that resemble ruminative patterns. Instead of automatically and repeatedly ruminating over negative thoughts that are clouded by assumptions and expectations, those who practise mindfulness enhance their ability to consciously respond and skilfully redirect their 
attention to the present. The development of openness to experiences enables individuals to acknowledge mental events and impulses that arise in elaborative processing regardless of their desirability. As such, individuals are less likely to engage in maladaptive thought suppression or avoidance that may paradoxically increase their ruminative tendencies. ${ }^{43}$

Our findings also demonstrated an overall increase in memory specificity in the MBCT group, whereas the increase in memory specificity in the active control group despite a significant reduction in depressive symptoms was primarily due to a reduction in the proportion of the response of omission. This finding further confirms that AMS is not a mood-driven process. ${ }^{44}$ In the MBCT group, the overall improvement in AMS was characterised by a significant increase in the retrieval of specific autobiographical events that occurred within the course of a day. The MBCT group also showed a significant decrease in overgeneral autobiographical memories after intervention, with the proportion of the response of specific memories nearly doubled and the proportion of the response of semantic associates decreased by roughly $50 \%$.

One reason for MBCT to have a more prominent effect on semantic associates is related to the age-specific cognitive style of older adults. Ageing is associated with reduced access to specific episodic details, while semantic information is normally preserved..$^{45}$ Older adults tend to truncate their search in the first stage of the iterative search during the retrieval process and only access the semantic meaning of the search cue. This finding indicates that certain therapeutic components of MBCT facilitate older adults to retrieve and search beyond the semantic level and to access more specific memory representations.

The treatment effect of MBCT on AMS can be explained with the cultivation of awareness through mindfulness practices. Older adults tend to encode and process information in a more general and categoric style. ${ }^{14}$ Enhanced mindful attention to both internal and external experiences is particularly beneficial for depressed older adults. This enables older adults to notice specific details of their environment and ongoing experiences, along with the accompanying thoughts, emotions, and bodily sensations, as the event unfolds itself. Specific encoding of autobiographical events in combination with enhanced internal awareness may in turn facilitate specific retrieval of an emotional event and hence an increase in AMS after MBCT. ${ }^{46}$

Regarding the treatment effects on trait mindfulness, the reduction of the MAAS score was significantly greater in the MBCT group than in the active control group. This finding indicates that older adults with mild to moderate depression can increase mindfulness through training and practice. $^{28}$

This study has several limitations. The participants' depression history such as the age of onset and the presence of chronic distress was not explored. This could have affected their responsiveness to the interventions. In addition, no follow-up assessments were performed after the 8-week intervention. The permanence of the treatment effects remained questionable. It is not uncommon for improved outcome measures to return to baseline level, especially when mindfulness practices gradually subside. ${ }^{27}$ Further studies are warranted on the temperance of outcome measures about the continuation of mindfulness practices after intervention. The active control group was not a manualised or validated programme. It did not include a full-day programme, whereas the MBCT group included a full-day retreat in addition to the weekly sessions. Hence, the therapeutic benefits of MBCT may be inflated owing to longer therapeutic exposure. The generalisability of the findings may be compromised owing to the characteristics of the sample. Study outcomes may only be generalisable to Chinese older adults with relatively mild depressive symptoms.

\section{Conclusion}

Although both MBCT and active control programme decrease the severity of depressive symptoms in older adults, only MBCT improves AMS, rumination, and mindfulness. Our findings provide empirical support for the theoretical underpinnings of MBCT. MBCT requires extensive teacher training and practice-friendly locations, whereas lowintensity active control exercise programme requires lower costs. Older adults with more severe depression and more severe dysfunctional cognition may benefit more from the specific therapeutic effects of MBCT.

\section{Acknowledgements}

The authors would like to thank Dr Yip Wai Kin and Mr John Leung for conducting the MBCT and physical exercise programmes, respectively. We are also thankful for colleagues at St James Settlement Central \& Western District Elderly Community Centre, Hong Kong Sheng Kung Hui Western District Elderly Community Centre, Holy Nativity Church Ming Wah Social Centre for the Elderly, Pok Oi Hospital Mr Kwok Hing Kwan Neighbourhood Elderly Centre, and Caritas Cheng Shing Fung District Elderly Centre for their kind assistance in recruitment and logistics. Lastly, our gratefulness extends to all the participants for their tremendous support.

\section{Declaration}

The authors have no conflict of interest to disclose.

\section{References}

1. Horackova K, Kopecek M, Machů V, Kagstrom A, Aarsland D, Motlova LB, et al. Prevalence of late-life depression and gap in mental health service use across European regions. Eur Psychiatry 2019;57:19-25. Crossref 
2. Tedeschini E, Levkovitz Y, Iovieno N, Ameral VE, Nelson JC, Papakostas GI. Efficacy of antidepressants for late-life depression: a meta-analysis and meta-regression of placebo-controlled randomized trials. J Clin Psychiatry 2011;72:1660-8. Crossref

3. Ricarte J, Ros L, Serrano JP, Martínez-Lorca M, Latorre JM. Age differences in rumination and autobiographical retrieval. Aging Ment Health 2016;20:1063-9. Crossref

4. von Hippel W, Vasey MW, Gonda T, Stern T. Executive function deficits, rumination and late-onset depressive symptoms in older adults. Cogn Ther Res 2008;32:474-87. Crossref

5. Nolen-Hoeksema $S$. The role of rumination in depressive disorders and mixed anxiety/depressive symptoms. J Abnorm Psychol 2000;109:50411. Crossref

6. Nolen-Hoeksema S, Morrow J. A prospective study of depression and posttraumatic stress symptoms after a natural disaster: the 1989 Loma Prieta Earthquake. J Pers Soc Psychol 1991;61:115-21. Crossref

7. Van Moorleghem K, Conniff K. Rumination in Geriatric Depression. In: Pachana NA, editor. Encyclopedia of Geropsychology. Springer; 2017:2092-8. Crossref

8. Van Vreeswijk MF, De Wilde EJ.Autobiographical memory specificity, psychopathology, depressed mood and the use of the Autobiographical Memory Test: a meta-analysis. Behav Res Ther 2004;42:73143. Crossref

9. Williams JM, Barnhofer T, Crane C, Herman D, Raes F, Watkins E, et al. Autobiographical memory specificity and emotional disorder. Psychol Bull 2007;133:122-48. Crossref

10. Conway MA, Pleydell-Pearce CW. The construction of autobiographical memories in the self-memory system. Psychol Rev 2000;107:261-88. Crossref

11. Williams JM. Capture and rumination, functional avoidance, and executive control (CaRFAX): three processes that underlie overgeneral memory. Cogn Emot 2006;20:548-68. Crossref

12. Lockwood KA, Alexopoulos GS, van Gorp WG. Executive dysfunction in geriatric depression. Am J Psychiatry 2002;159:1119-26. Crossref

13. Ros L, Latorre JM, Serrano JP. Working memory capacity and overgeneral autobiographical memory in young and older adults. Neuropsychol Dev Cogn B Aging Neuropsychol Cogn 2010;17:89107. Crossref

14. Craik FI, Simon E. Age differences in memory: the roles of attention and depth of processing in new directions in memory and aging. Talland Memorial Conference 1980:95-112.

15. Morcom AM, Good CD, Frackowiak RS, Rugg MD. Age effects on the neural correlates of successful memory encoding. Brain 2003;126:21329. Crossref

16. Anderson ND, Lau MA, Segal ZV, Bishop SR. Mindfulness-based stress reduction and attentional control. Clin Psychol Psychother 2007;14:449-63. Crossref

17. Koster EH, De Lissnyder E, Derakshan N, De Raedt R. Understanding depressive rumination from a cognitive science perspective: the impaired disengagement hypothesis. Clin Psychol Rev 2011;31:13845. Crossref

18. Heeren A, Van Broeck N, Philippot P. The effects of mindfulness on executive processes and autobiographical memory specificity. Behav Res Ther 2009;47:403-9. Crossref

19. Hitchcock C, Hammond E, Rees C, Panesar I, Watson P, Werner-Seidler A, et al. Memory Flexibility training (MemFlex) to reduce depressive symptomatology in individuals with major depressive disorder: study protocol for a randomised controlled trial. Trials 2015;16:494. Crossref

20. Segal ZV, Williams JMG, Teasdale JD. Mindfulness-Based Cognitive Therapy for Depression: a New Approach to Preventing Relapse. Guilford Press; 2002.

21. Chiesa A, Castagner V, Andrisano C, Serretti A, Mandelli L, Porcelli S, et al. Mindfulness-based cognitive therapy vs. psycho-education for patients with major depression who did not achieve remission following antidepressant treatment. Psychiatry Res 2015;226:47483. Crossref

22. Piet J, Hougaard E. The effect of mindfulness-based cognitive therapy for prevention of relapse in recurrent major depressive disorder: a systematic review and meta-analysis. Clin Psychol Rev 2011;31:103240. Crossref

23. Eisendrath SJ, Gillung E, Delucchi KL, Segal ZV, Nelson JC, McInnes LA, et al. A randomized controlled trial of mindfulnessbased cognitive therapy for treatment-resistant depression. Psychother Psychosom 2016;85:99-110. Crossref

24. Michalak J, Hölz A, Teismann T. Rumination as a predictor of relapse in mindfulness-based cognitive therapy for depression. Psychol Psychother 2011;84:230-6. Crossref

25. Barnhofer T, Crane C, Hargus E, Amarasinghe M, Winder R, Williams JM. Mindfulness-based cognitive therapy as a treatment for chronic depression: a preliminary study. Behav Res Ther 2009;47:36673. Crossref

26. Shahar B, Britton WB, Sbarra DA, Figueredo AJ, Bootzin RR. Mechanisms of change in mindfulness-based cognitive therapy for depression: preliminary evidence from a randomized controlled trial. Int J Cogn Ther 2010;3:402-18. Crossref

27. O'Connor M, Piet J, Hougaard E. The effects of mindfulness-based cognitive therapy on depressive symptoms in elderly bereaved people with loss-related distress: a controlled pilot study. Mindfulness 2014;5:400-9. Crossref

28. Splevins K, Smith A, Simpson J. Do improvements in emotional distress correlate with becoming more mindful? A study of older adults. Aging Ment Health 2009;13:328-35. Crossref

29. Torres-Platas SG, Escobar S, Belliveau C, Wu J, Sasi N, Fotso J, et al. Mindfulness-based cognitive therapy intervention for the treatment of late-life depression and anxiety symptoms in primary care: a randomized controlled trial. Psychother Psychosom 2019;88:2546. Crossref

30. Zhang JX, Liu XH, Xie XH, Zhao D, Shan MS, Zhang XL, et al. Mindfulness-based stress reduction for chronic insomnia in adults older than 75 years: a randomized, controlled, single-blind clinical trial. Explore (NY) 2015;11:180-5. Crossref

31. de Maat SM, Dekker J, Schoevers RA, de Jonghe F. Relative efficacy of psychotherapy and pharmacotherapy in the treatment of depression: a meta-analysis. Psychother Res 2006;16:566-78. Crossref

32. Hamilton M. A rating scale for depression. J Neurol Neurosurg Psychiatry 1960;23:56-62. Crossref

33. Zheng YP, Zhao JP, Phillips M, Liu JB, Cai MF, Sun SQ, et al. Validity and reliability of the Chinese Hamilton Depression Rating Scale. Br J Psychiatry 1988;152:660-4. Crossref

34. Huang LJ, Wu CY, Wu CH, Huang PS, Yeh HH, Yang YH, et al. Validation of the Ruminative Response Scale-Chinese Version (RRS-C) for persons with depression in Taiwan. Taiwan J Psychiatry (Taipei) 2015;29:119-31.

35. Williams JM, Broadbent K. Autobiographical memory in suicide attempters. J Abnorm Psychol 1986;95:144-9. Crossref

36. Brown KW, Ryan RM. The benefits of being present: mindfulness and its role in psychological well-being. J Pers Soc Psychol 2003;84:82248. Crossref

37. Deng YQ, Li S, Tang YY, Zhu LH, Ryan R, Brown K. Psychometric properties of the Chinese translation of the mindful attention awareness scale (MAAS). Mindfulness 2012;3:10-4. Crossref

38. Wong A, Xiong YY, Kwan PW, Chan AY, Lam WW, Wang K, et al. The validity, reliability and clinical utility of the Hong Kong Montreal Cognitive Assessment (HK-MoCA) in patients with cerebral small vessel disease. Dement Geriatr Cogn Disord 2009;28:81-7. Crossref

39. Sterne JA, White IR, Carlin JB, Spratt M, Royston P, Kenward MG, et al. Multiple imputation for missing data in epidemiological and clinical research: potential and pitfalls. BMJ 2009;338:b2393. Crossref

40. Perestelo-Perez L, Barraca J, Peñate W, Rivero-Santana A, AlvarezPerez Y. Mindfulness-based interventions for the treatment of depressive rumination: systematic review and meta-analysis. Int J Clin Health Psychol 2017;17:282-95. Crossref

41. Thomsen DK, Mehlsen MY, Olesen F, Hokland M, Viidik A, Avlund $\mathrm{K}$, et al. Is there an association between rumination and self- 
reported physical health? A one-year follow-up in a young and an elderly sample. J Behav Med 2004;27:215-31. Crossref

42. Bishop SR, Lau M, Shapiro S, Carlson L, Anderson ND, Carmody J, et al. Mindfulness: a proposed operational definition. Clin Psychol Sci Pract 2004;11:230-41. Crossref

43. Erber R, Wegner DM. Ruminations on the Rebound. Lawrence Erlbaum Associates 1996:73-9.

44. Brittlebank AD, Scott J, Williams JM, Ferrier IN. Autobiographical memory in depression: state or trait marker? $\mathrm{Br} \mathrm{J}$ Psychiatry 1993;162:118-21. Crossref

45. Levine B, Svoboda E, Hay JF, Winocur G, Moscovitch M. Aging and autobiographical memory: dissociating episodic from semantic retrieval. Psychol Aging 2002;17:677-89. Crossref

46. Williams JMG, Teasdale JD, Segal ZV, Soulsby J. Mindfulness-based cognitive therapy reduces overgeneral autobiographical memory in formerly depressed patients. J Abnorm Psychol 2000;109:150-55. Crossref 